\title{
COMMENTARY
}

\section{Purposeful Imprinting in Graduate Medical Education: Opportunities for Partnership}

Robert L. Phillips, Jr, MD, MSPH; Eric S. Holmboe, MD, MACP; Andrew W. Bazemore, MD, MPH; Brian C. George, MD, MA

(Fam Med. 2021;53(7):574-7.)

doi: 10.22454/FamMed.2021.264013

Published Online First May 10, 2021

"Children have never been very good at listening to their elders, but they have never failed to imitate them." - James Baldwin ${ }^{1,2}$

\section{Imprinting in Medical Education}

Imprinting is a psychological term for "the process by which an organism develops a tendency to remain in proximity with the first stimuli to which it is exposed." Imprinting stimuli are more or less constant during a very critical period of early development, and unlike associative learning, are not induced by consequences (either rewards or negative feedback). Imprinting comes from stimuli that are early, immersive, and innately comfortable. Similar effects are seen in medical education. Some have referred to imprinting as a "hidden curriculum" that exists in both medical school and graduate medical education (GME), potentially trumping the actual curriculum in terms of lasting impact on practice. ${ }^{1,4}$

Quantifying and assessing imprinting is an emerging science in health professions education, but early studies suggest its effects are significant and enduring. For example, the imprint of health care cost behaviors acquired during residency lasts at least 16-19 years posttraining. ${ }^{5,6}$ Medical student cost-related behaviors appear to be similarly influenced by those of their training institution. ${ }^{7}$ Educational imprinting also impacts the scope of practice, with both positive and negative effects on value and overall care provided to patients. ${ }^{8}$ Other studies further inform this vision, for example: (1) a likely imprint of patient management style and general internists' choices of conservative vs aggressive management options ${ }^{9}$; (2) practice intensity (aggressiveness) is largely predicted by residency affiliation ${ }^{10}$; and (3) Asch et al reported imprinting of quality of care for women treated by obstetricians, specifically maternity care complications. ${ }^{11}$ Relatedly, training in rural and safety-net settings has been shown to be a potent predictor in practicing in these settings later. ${ }^{12}$ Imprinting can be general (management approach, costs of care) to specific (procedural competence), but both likely benefit from pattern consistency assessment across trainees rather than assessing at the level of the individual trainee.

Ongoing research will continue to deepen our understanding of which outcomes are imprinted, how to modify them in the training environment, and how to modify them in practice.

\section{Harnessing Purposeful Imprinting}

The promise of purposeful imprinting is a future consistent with Hafferty's vision for

reform initiatives... undertaken with an eye to what residents learn, instead of what they are taught. ${ }^{13}$

From the American Board of Family Medicine (Drs Phillips and Bazemore); Accreditation Council for Graduate Medical Education (Dr Holmboe); and University of Michigan Department of Surgery (Dr George). 
Some medical educators already propose using this powerful driver of future clinician behavior to align educational and clinical contexts, hoping to

establish a training environment that supports bridging from clinician to educator, training program to clinical microsystem, and educational outcomes to clinical outcomes that benefit the patient. ${ }^{14}$

Building on the concept that "the clinic is the curriculum," they seek to change the clinical environment to reinforce desirable behaviors by modeling professional behaviors in the clinical learning environment. ${ }^{15}$ It is for this reason that the American Board of Family Medicine now requires quality improvement activities during residency, not only to affect resident learning, but to induce modeling behaviors by the faculty and institutions that make it a part of the formal education program and their own practice.

While the potential impact of aligning the clinical and educational contexts are clear, effective implementation poses challenges. For example, while Asch et al found evidence of procedural quality imprinting, Phillips et al did not find evidence of imprinting for chronic disease quality measures. ${ }^{5,11}$ Perhaps obstetrical procedures are imprinted through repeated modeling whereas there is less opportunity for recurrent modeling of chronic care management or instruction on disease quality assessment and improvement. The Institute for Healthcare Improvement and others have implementation models for clinical improvement that might support clinical quality imprinting, and educators have recently drawn parallels between quality improvement and medical education (experiencing, reflecting, thinking, and acting in continuous cycles). ${ }^{16}$ It may be useful for faculty to decide on the behaviors or traits that they most wish to imprint (and those they don't) and then focus on how to make the training practice an immersive experience- - how the things they do every day in practice specifically reinforce those behaviors.

\section{Partnership Opportunities for Accreditation, Certification, and Training Funding}

Jordan Cohen, MD, former president of the Association of American Medical Colleges, once noted, "the residency experience inevitably brands all physicians with an indelible imprint of medicine's lived values." ${ }^{.17}$ While there is evidence that imprinting starts in medical school, there are clear opportunities for the Accreditation Council on Graduate Medical Education (ACGME), certifying boards, and training funding to work in concert to promote the imprinting of desirable behaviors. Regulators have begun to recognize their role in shaping the environments in which physicians train, ensuring the imprint of behaviors desired by patients and communities. Regulation may be particularly valuable where health systems interests risk imprinting undesirable behaviors. Regulation can help shape a clinical training built environment that aligns intrinsic and extrinsic drivers of behavior so that physicians are nudged toward the right choice because it is the easy choice. ${ }^{18}$ Accreditation and certification requirements could focus on built environment features that must be present because they demonstrate desirable practice behavior imprinting. For primary care this could be empanelment and continuity threshold requirements, for example.

In 2004, ACGME Executive Director David Leach called for changes in residency education accreditation that offered

more emphasis on educational outcomes and less on process, more external and fewer internal measures, greater recognition of the continuum of medical education, more links between the quality of education and the quality of patient care.

He went on to forecast,

(i)n the future, accreditation will be much more selective in its process measures and will probe educational outcome measures in depth.

That shift has begun. For the past decade, the ACGME outcome focus has been on competence, quality, and safety, best encompassed by the introduction of competency Milestones and the Clinical Learning Environment Review (CLER) program (quality and safety). ${ }^{19}$ CLER has particular relevance to imprinting, as it grew out of concerns about the supervision and quality of care provided by institutions and their subsequent effects on learner outcomes. ${ }^{11}$ CLER might be leveraged to more deliberately harness institution-level capacity for positive imprinting, while Milestones could focus more on individual competencies that might be a signal for imprinting improvement (see the Asch example for obstetrics). 
New approaches to measurement will also be important. Dr Leach proposed regular surveys of graduated residents and existing trainees. Family medicine has implemented this idea and is the only specialty that requires training programs to survey graduates. The American Board of Family Medicine (ABFM) systematized this, surveying all graduating residents about their preparation, plans for practice, and burnout. It is a mandatory survey for initial certification and has been used extensively to assess practice vs training scope of practice. ${ }^{8}$ The ABFM resurveys graduates 3 years later asking related questions. ${ }^{20}$ These two surveys now populate annual reports to training programs, but could be a more robust part of the accreditation feedback loops, aiming to improve the training environment. Other certifying boards are collaborating with the ACGME, particularly around understanding Milestones and associated outcomes, and there is opportunity to support assessments of imprinted training outcomes.

The mounting evidence of imprinted costrelated and quality behaviors suggest several meaningful measures that may be assessed after training that reflect on the training environment. For example, efforts to translate the dimensions that explain primary care's beneficial effects on health-first contact, cost, continuity, and comprehensiveness-into measures are not only applicable to value-based physician payment, but also may prove important in evaluating training programs. ${ }^{21-23}$ The time is ripening for relating practice behaviors and competencies back to programs to look for opportunities to improve training.

To realize any of these changes, it is critical that GME funders recognize their strong incentive to measure training outcomes and for joining accreditation and certification bodies in influencing training environments. Among federal stakeholders, the Health Resources and Services Administration (HRSA) has capitalized on the imprinting effects of training in safety net and rural settings in support of its Teaching Health Center and rural training programs. HRSA is also first among GME funders to pilot value-based payment for training institutions, through its Childrens Hospital Graduate Medical Education Quality Bonus System. ${ }^{24}$ While HRSA continues to assess the general effectiveness of its programs, it could develop site-level training outcome measures for desirable behavior imprinting to focus its investments and guide training site improvements. ${ }^{25}$ The Veterans Health Administration spends upwards of $\$ 2$ billion on GME with very little assessment of training outcomes, imprinted or otherwise. The Centers for Medicare \& Medicaid Services put $\$ 12$ billion annually into GME, but lack authority to assess or direct training outcomes. ${ }^{26}$ The data and methods for evaluating training outcomes, some of which are clearly imprinted, are available. ${ }^{27}$ The primary funders of GME may need both more information and more authority to be effective partners in this work.

\section{Conclusion}

Educational imprinting in residency education has significant effects on practice, and hence, on the health of our society. Imprinting can be positively harnessed by implementing changes in educational clinical settings. There are clear and important partnerships available to work on this important driver and outcome of medical education.

CORRESPONDING AUTHOR: Address correspondence to Dr Robert L. Phillips, Jr, Executive Director, The Center for Professionalism \& Value in Health Care, American Board of Family Medicine, 1016 NW 16th St, Suite 700, Washington, DC 20036. 202-494-0512. bphillips@theabfm.org.

\section{References}

1. Dhaliwal G. The greatest generation. JAMA. 2015;314(22):2353-2354. doi:10.1001/jama.2015.10622

2. Baldwin J. Fifth Avenue, Uptown: A Letter From Harlem. In: Baldwin J. Nobody Knows My Name. New York: Dial Press; 1961.

3. Salk L. Thoughts on the concept of imprinting and its place in early human development. Can Psychiatr Assoc J. 1966;11(1)(suppl):295-305. doi:10.1177/070674376601101S41

4. Hafferty FW, Franks R. The hidden curriculum, ethics teaching, and the structure of medical education. Acad Med. 1994;69(11):861-871. doi:10.1097/00001888-199411000-00001

5. Phillips RL Jr, Petterson SM, Bazemore AW, Wingrove P, Puffer JC. The effects of training institution practice costs, quality, and other characteristics on future practice. Ann Fam Med. 2017;15(2):140-148. doi:10.1370/afm.2044

6. Chen C, Petterson S, Phillips R, Bazemore A, Mullan F. Spending patterns in region of residency training and subsequent expenditures for care provided by practicing physicians for Medicare beneficiaries. JAMA. 2014;312(22):23852393. doi:10.1001/jama.2014.15973

7. Leep Hunderfund AN, Starr SR, Dyrbye LN, et al. Imprinting on clinical rotations: multisite survey of high- and low-value medical student behaviors and relationship with healthcare intensity. J Gen Intern Med. 2019;34(7):1131-1138. doi:10.1007/s11606-019-04828-8

8. Coutinho AJ, Levin Z, Petterson S, Phillips RLJ Jr, Peterson LE. Residency program characteristics and individual physician practice characteristics associated with family physician scope of practice. Acad Med. 2019;94(10):1561-1566. https:// journals.lww.com/academicmedicine/Fulltext/2019/10000/ Residency_Program_Characteristics_and_Individual.38.aspx doi:10.1097/ACM.0000000000002838 
9. Sirovich BE, Lipner RS, Johnston M, Holmboe ES The association between residency training and internists' ability to practice conservatively. JAMA Intern Med. 2014;174(10):1640-1648. doi:10.1001/jamainternmed.2014.3337

10. Dine CJ, Bellini LM, Diemer G, et al. Assessing correlations of physicians' practice intensity and certainty during residency training. J Grad Med Educ. 2015;7(4):603-609. doi:10.4300/JGME-D-15-00092.1

11. Asch DA, Nicholson S, Srinivas S, Herrin J, Epstein AJ. Evaluating obstetrical residency programs using patient outcomes. JAMA. 2009;302(12):1277-1283. doi:10.1001/ jama.2009.1356

12. Phillips RL, Petterson S, Bazemore A. Do residents who train in safety net settings return for practice? Acad Med. 2013;88(12):1934-1940. doi:10.1097/ACM.0000000000000025

13. Hafferty FW. Beyond curriculum reform: confronting medicine's hidden curriculum. Acad Med. 1998;73(4):403-407. doi:10.1097/00001888-199804000-00013

14. Wong BM, Holmboe ES. Transforming the academic faculty perspective in graduate medical education to better align educational and clinical outcomes. Acad Med. 2016;91(4):473479. doi:10.1097/ACM.0000000000001035

15. Baxley EG. The clinic is the curriculum: can attention to the clinical Learning environment enhance improvement in health care delivery and outcomes? J Am Board Fam Med. 2020;33(suppl):S46-S49. doi:10.3122/jabfm.2020.S1.190447

16. Wong BM, Headrick LA. Application of continuous quality improvement to medical education. Med Educ. 2020; 55 72-81. doi:10.1111/medu.14351

17. Cohen JJ. Honoring the "E" in GME. Acad Med. 1999;74(2):108-113. doi:10.1097/00001888-199902000-00009

18. Phillips RL Jr, Bazemore AW, Newton WP. Pursuing practical professionalism: form follows function. Ann Fam Med. 2019;17(5):472-475. doi:10.1370/afm.2457

19. Nasca TJ, Philibert I, Brigham T, Flynn TC. The next GME accreditation system-rationale and benefits. N Engl J Med. 2012;366(11):1051-1056. doi:10.1056/NEJMsr1200117
20. Peterson LE, Fang B, Phillips RL Jr, Avant R, Puffer JC. The American Board of Family Medicine's data collection method for tracking their specialty. J Am Board Fam Med. 2019;32(1):89-95. doi:10.3122/jabfm.2019.01.180138

21. Shuemaker JC, Phillips RL Jr, Newton WP. From the American Board of Family Medicine: clinical quality measures in a post-pandemic world: measuring what matters in family medicine. Ann Fam Med. 2020;18(4):380-382. doi:10.1370/ afm. 2564

22. Bazemore A, Petterson S, Peterson LE, Bruno R, Chung Y, Phillips RL Jr. Higher primary care physician continuity is associated with lower costs and hospitalizations. Ann Fam Med. 2018;16(6):492-497. doi:10.1370/afm.2308

23. Bazemore A, Petterson S, Peterson LE, Phillips RL Jr. More comprehensive care among family physicians is associated with lower costs and rewer hospitalizations. Ann Fam Med. 2015;13(3):206-213. doi:10.1370/afm.1787

24. Fujioka S. HRSA's Response on The Establishment of the CHGME Quality Bonus System. GME Solutions. http://gmesolutions.com/hrsa-response-chgme-quality-bonus-system/. Published July 28, 2018. Accessed January 6, 2021.

25. Lee M, Newton H, Smith T, et al. The benefits of physician training programs for rural communities: lessons learned from the Teaching Health Center Graduate Medical Education Program. J Health Care Poor Underserved. 2016;27(4A):83-90. doi:10.1353/hpu.2016.0184

26. Verma S. Letter to the Honorable Charles E. Grassley, Chairman, Committee on Finance. United States Senate. https:// www.finance.senate.gov/imo/media/doc/Chairman\%20Grassley\%20GME\%20Response.pdf. Published online January 6 2020. Accessed November 22, 2020.

27. Weinstein DF. Optimizing GME by measuring its outcomes. N Engl J Med. 2017;377(21):2007-2009. doi:10.1056/ NEJMp1711483 